\title{
Extraction \& Processing Division: Meeting the Needs of Current and Future Extractive Professionals
}

\author{
Thomas P. Battle
}

For the past three years I've been privileged to be the chair of the Extraction

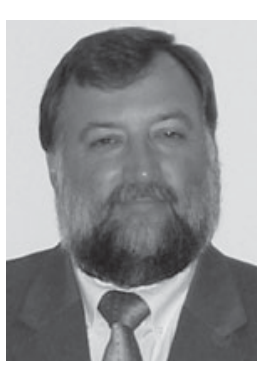

\& Processing Division (EPD), one of the five technical divisions in TMS. I am following in the footsteps of several outstanding leaders who chaired the division before me, including Chuck Bounds, Bill Imrie, John Hager, Brajendra Mishra, and Rob Stephens.

The EPD represents about 1,000 TMS members from all over the world. Unfortunately, in recent years our membership ranks have declined, while the average age of our members has increased. This coincides with a general decline in the number of extractive metallurgists in the United States, and in North America in general. Having a critical mass of active members, representing all different ages and areas of the field, is critical to keep us a vibrant organization. Many of our efforts in the past few years have been aimed at improving our services to current members, encouraging current members to become more active as volunteers, and enlisting new members. At the grass-roots level, we enthusiastically participate in the TMS Young Leaders (YL) program, and have two fine YLs at present, with hopefully more to join them later this year. This has been a significant avenue for participation in our organization-over half of the current EPD Council members were YLs, and their enthusiasm has been instrumental in our success. We are also actively involved in the student scholarship program, and working hard to encourage Student Poster Session submissions.

At a higher level we are also aware that we aren't the only professional or- ganization in North America that caters to the extraction and processing of metals. The closest to us are the Society for Mining, Metallurgy, \& Exploration (SME) and The Metallurgical Society of CIM (MetSoc). Although SME has its roots in exploration and mining, there is an obvious overlap in the mineral processing and extractive metallurgy areas. MetSoc is more akin to TMS and the Association for Iron and Steel Technology combined, with programs from metals to materials, ferrous and non-ferrous alike. The EPD has many common members with SME and MetSoc, and has conducted joint programming in the past. However, on a number of occasions the services between the societies have conflicted, and the extractive metallurgy community has suffered. Two approaches have been made to avoid future conflicts.

First, TMS and SME recently signed a Memorandum of Understanding that will encourage direct discussions on annual meeting programming between the two societies, with the goal of keeping meetings at least two weeks apart. We will also consider co-locating our annual meetings whenever it makes sense. Given the long lead time for reserving convention centers and hotels, the first year we might be able to co-locate is 2019. In the near term, ongoing discussions at the staff level will improve our ability to coordinate activities with each other, for the benefit of all members.

Second, representatives from the three societies met with a facilitator in Toronto in August 2009, to discuss our past issues, present opportunities, and future challenges. The result was a renewed understanding of the issues and a sense of purpose, and a clear agreement that the three societies should be collaborating, not competing. From the discussion grew the concept of the North American Extractive Metallurgy Council. This organization was chartered by the three parent societies as a way to coordinate our efforts to serve extractive metallurgists in North America and worldwide; I am honored to be the lead TMS representative to the council. We have been communicating by e-mail and conference call for the last year, with a face-to-face meeting at the TMS meeting in Seattle last winter, and another at the MetSoc annual meeting in Vancouver last month. We have covered a lot of ground in the meetings, particularly around programming collaboration for both regular meetings and specialty conferences. If you wish to help us determine what can be of use to you as an extractive metallurgist, feel free to fill out our survey at www. surveymonkey.com/s/naemc.

We also continue with our general work in the extractive metallurgy of non-ferrous metals. We have six active technical committees-three that are solely EPD (Pyrometallurgy, Hydrometallurgy/Electrometallurgy, Materials Characterization), and three shared with other divisions (Energy and Recycling and Environmental Technologies, with LMD, and Process Technology and Modelling, with MPMD). They continue to work on developing quality programming, publishing well-regarded conference proceedings, recognizing our colleagues worldwide for their contributions to the field, and generally making my job a pleasure. I will miss all the interactions and stimulation when I turn over the gavel to the incoming chair, Adrian Deneys, in San Diego next February.

Tom Battle is a senior metallurgist with Midrex Technologies and chair of the TMS Extraction \& Processing Division. 